\title{
A review of community-based solar home system projects in the Philippines
}

\author{
Erees Queen B. Macabebe ${ }^{1,2}$, Reynaldo C. Guerrero, Jr. ${ }^{2}$, Aleta C. Domdom ${ }^{3}$, Aison S. Garcia ${ }^{2}$, Emma E. Porio ${ }^{4}$, \\ Samuel Matthew G. Dumlao ${ }^{1}$ and Teresita R. Perez ${ }^{5}$ \\ ${ }^{1}$ Ateneo de Manila University, Department of Electronics, Computer, and Communications Engineering, Quezon City 1108 Philippines \\ ${ }^{2}$ Solarsolutions, Inc., Quezon City 1108 Philippines \\ ${ }^{3}$ Ateneo de Manila University, Department of Economics, Quezon City 1108 Philippines \\ ${ }^{4}$ Ateneo de Manila University, Department of Sociology and Anthropology, Quezon City 1108 Philippines \\ ${ }^{5}$ Ateneo de Manila University, Department of Environmental Sciences, Quezon City 1108 Philippines
}

\begin{abstract}
Solar Home Systems (SHS) are easy to deploy in island and in remote communities where grid connection is costly. However, issues related to maintenance of these systems emerge after they are deployed because of the remoteness and inaccessibility of the communities. This study looked into community-based programs in the Philippines and investigated the following: (1) social preparation, (2) role of the community in the project, and (3) sustainability of the program. In this paper, three communities under two government programs offering SHS are presented. These programs are the Solar Power Technology Support (SPOTS) program of the Department of Agrarian Reform (DAR) and the Household Electrification Program (HEP) of the Department of Energy (DOE). A focused group discussion and key informant interviews were conducted in two communities in Bukidnon province and in a community in Kalinga to obtain information from the project beneficiaries and SHS users on the preparation, implementation and maintenance of the projects. The results revealed that emphasis on the economic value of the technology, proper training of the locals on the technical and management aspects of the project, as well as the establishment of a supply chain for replacement parts are crucial factors for the sustainability of the programs.
\end{abstract}

\section{Introduction}

Solar energy is the least tapped of all the renewable energy sources in the Philippines. In the 2013 Energy Sector Accomplishment Report of the Department of Energy, the country's primary energy supply in 2012 reached 42.90 million tons of oil equivalent (MTOE). Figure 1 shows the primary supply mix with about $45.98 \%$ of the energy supply coming from renewable and natural gas sources. Geothermal power having the biggest share at $20.55 \%$ while solar/wind contributes a meager $0.02 \%$.

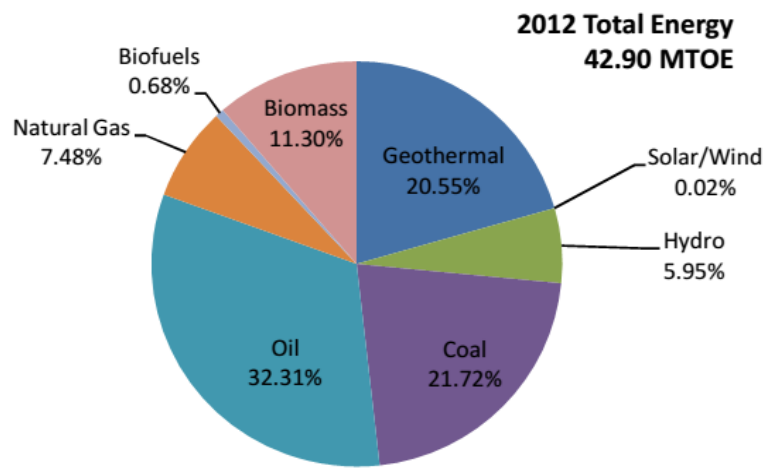

Figure 1. 2012 Primary Energy Supply Mix [1]
However, solar remains the most viable renewable energy source in the country. The use of solar photovoltaic systems in off-grid communities is most appropriate because the Philippines is near the equator, between $5^{\circ} \mathrm{N}$ and $20^{\circ} \mathrm{N}$ latitude, and the country receives an annual average of between $4.5-5.5 \mathrm{kWh} / \mathrm{m}^{2} /$ day of solar energy. Figure 2 shows the map of the solar energy potential of the country using the Climatological Solar Radiation Model in a resource assessment conducted by NREL [2].

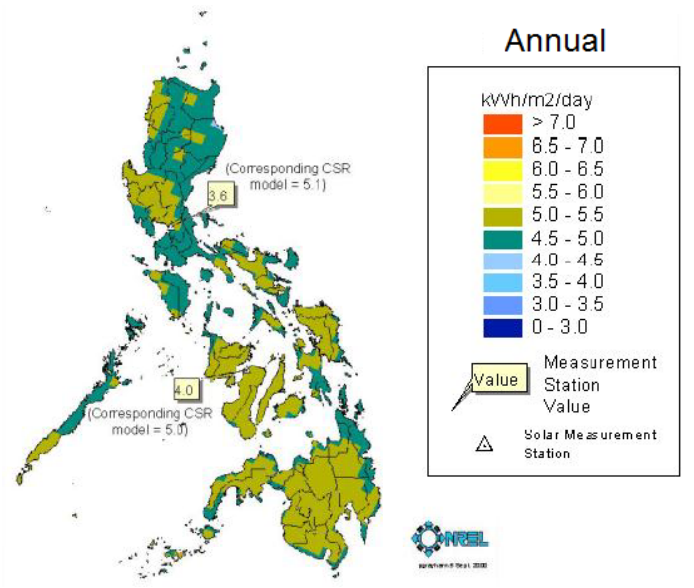

Figure 2. Solar energy potential of the Philippines 
The DAR-SPOTS program is an integrated social and agricultural project [3]. The primary objectives of the program were economic and social in nature, which includes the following: (1) Address poverty in the unenergized and off-grid agrarian reform communities (ARCs) through the introduction of specific PV applications in agriculture and rural enterprise development, (2) Increase agricultural productivity and promote economic/livelihood diversification, (3) Capacitate and empower local communities and organization in the ARCs, (4) Apply solar power as enabling technology to promote sustainable development.

To achieve the objectives of the program, the following were undertaken: (1) solar electrification which includes installation, commissioning and hand-over of solar packages to recipient communities, (2) agricultural and rural enterprise development, and (3) institutional development such as formation of People's Organization (PO) in all beneficiary communities and PO capacity building. The target beneficiaries are Agrarian Reform Communities (ARC) in the country and one of the selection criteria is their non-inclusion in electrification projects of other agencies such as DOE and NEA.

THE DOE-HEP involves energizing off-grid households using mature renewable energy technologies such as photovoltaic in SHS and streetlights, and microhydro systems [4]. The aim is to address the electrification needs of households in areas where grid connection is currently not feasible. This program was designed to contribute to attaining the target of $90 \%$ household electrification nationwide by 2017 . Through this program, DOE plans to contribute at least 2,000 households every year to achieve the target.

HEP was funded by the national government subsidies from the DOE's Special Account in the General Fund (Fund 151). Thus, DOE directly implemented HEP through its three field offices across the country. The DOE was responsible for hardware procurement, shipment and installation of the power systems. It provided technical training of users and technicians. DOE field personnel conducted social preparation and community organizing in collaboration with Team Energy Foundation, Inc. The DOE assigned field personnel took charge of all stages of project activities: development and identification of beneficiaries, inventory, implementation, and monitoring. The DOE coordinated with the local government units (LGU) and the electric cooperatives (EC) during the implementation of the project.

Once the projects were completed, the DOE turned over the renewable systems to community power associations, composed of household beneficiaries, for operation and maintenance. The community associations are expected to manage and maintain the systems using the membership and maintenance fees to ensure the sustainability of the project.

The goal of this study is two-fold: to review the implementation procedure of the SHS projects, and to find out what measures are undertaken by the community to maintain the SHS and sustain the program. Three communities were chosen as study sites: two beneficiaries of DAR-SPOTS in the Municipality of
Kadingilan in Bukidnon Province and the third community is a beneficiary of DOE-HEP located near the boundary of Tabuk City, Kalinga and Paracelis, Mountain Province.

\section{Methodology}

Site visits were made for data collection and field study. In-depth interview and focused group discussions (FGD) were conducted in each case study sites with at least 10 participants from the community and members of the cooperatives. Also Key Informant Interviews with implementing agencies, NGOs and relevant local government units were conducted to gather information on the projects. Data triangulation was conducted by reviewing accomplishment reports and documents obtained from stakeholders, the government agencies responsible in the implementation of the program, as well as third party reports to verify the information from different sources. The case studies focused on four questions. (1) What was the role of the community in the project? (2) How were they prepared before the technology was introduced? (3) How did they adapt to the technology and what efforts were undertaken by the community to sustain the project? (4) What support did they get from the implementing agency to sustain the project?

The impact of the programs and projects were analysed by considering the following key aspects of sustainability: technology and the capacity of the community members to learn the skills required to operate and maintain the SHS, environmental, social and economic. These key aspects were analyzed following the Five Level Framework [5] which looks into (1) Systems level - the set-up or equipment in the selected area, (2) Success level - what the community or agency wants to achieve for the project, (3) Strategic level - guiding principles during the implementation, (4) Actions level actions done to achieve the goal of the project, and (5) Tools level - tools used to achieve the goal of the project.

\section{Results and Discussion}

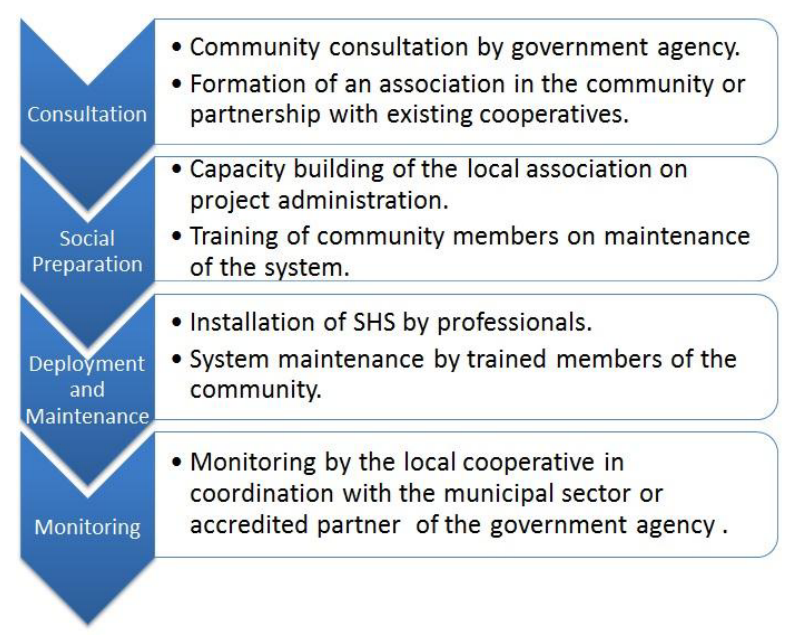

Figure 3. Project implementation flow followed by both government programs. 
In both programs, the government agencies involved followed a similar procedure in implementing the projects. It followed the paradigm in Figure 3 where community consultations and trainings were conducted prior to system deployment. One key aspect in these projects is that to qualify for the program, a local cooperative or an association is required to operate the project and maintain the SHS in the community [3, 4].

\subsection{Kadingilan Municipality: Cabadiangan and Pay-as Agrarian Reform Communities}

Kadingilan is a third class municipality in the Province of Bukidnon in the Philippines. The topography of the municipality is mountainous and hilly characterized by rough terrain. According to the 2010 census [6], Kadingilan has 31, 756 residents distributed in 17 Barangays. Cabadiangan with 4, 521 residents and Pay-as with 1, 863 residents are two of the barangay beneficiaries of DAR-SPOTS. The two barangays are accessible from the town center via a dirt road. Figure 4 shows the participants of the focused group discussion that was conducted to gather information from the community for this project.

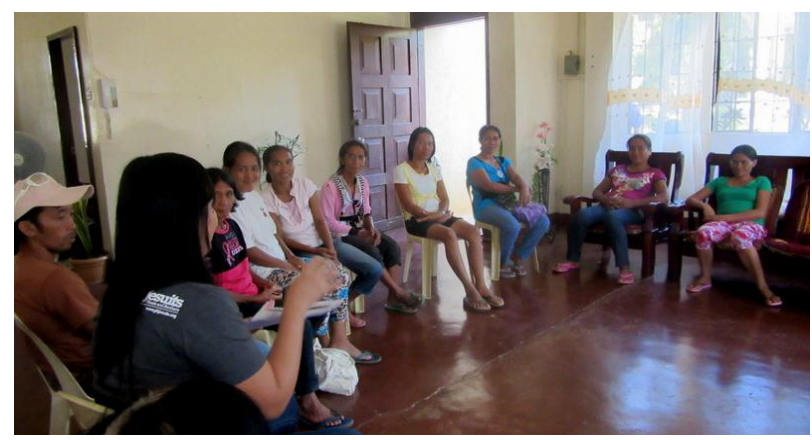

Figure 4. Community members from Pay-as gathered for the Focused Group Discussion.

Table 1 summarizes how the project was implemented in the two communities. Since SPOTS is a social and agricultural project, there were several consultations on the most appropriate rural enterprise that the community can engage in. Once the systems were turned over to the ARCs, they are responsible for the operations and maintenance of these systems.

To avail the SHS, one should be a member of the cooperative. To become a member, one has to undergo the Pre-membership education seminar (PMES) which includes an introduction on the role of cooperative members and their benefits. This is conducted by the officers of the cooperative and integrated into the seminar is the training on the maintenance of the SHS which includes battery care and cleaning of the solar PV module. This training is conducted by the technician.

A total of 187 availed of the SHS in Cabadiangan and Pay-as. Each household agreed to pay the cooperative a monthly subscription fee of Php 220.00 (USD 4.70) to cover the operations and maintenance costs of the solar PV systems. This amount is less than what the household would normally pay for in a month using kerosene lamps. A few years later, after consultation with DAR, the monthly fee was reduced to Php 110.00 (USD 2.35) in Cabadiangan and Php 100.00 (USD 2.13) in Pay-as on the condition that the cooperative will no longer be responsible for parts replacement like bulbs when they are damaged or no longer functional, and for the battery solution.

Table 1. DAR-SPOTS implementation in Cabadiangan and Pay-as.

\begin{tabular}{|l|l}
\hline & - In 2006, DAR conducted a survey and \\
consultation with the communities. \\
- Pay-as formed the Mountain Hilltop \\
Association and Cabadiangan under their \\
existing Cabadiangan Agrarian Reform \\
Beneficiaries Multipurpose Cooperative \\
were chosen beneficiaries of the program. \\
- Several consultations were conducted to \\
determine the most appropriate rural \\
enterprise for each community.
\end{tabular}

In Cabadiangan, the technician checks the battery every 3 months, whereas in Pay-as, the technician makes his round once every month. Also, the effectiveness of the response to complaints depends on the location of the household and the type of complaint. Households that are far from the barangay do not receive immediate support because of the travel time. In one of the cooperatives where the role of the technician has become voluntary, the response mechanism can take a few days.

The cooperative can pull-out the SHS from households who could not keep up with the payments, and from those households who have already connected to the electricity grid and chose to forego the SHS. The SHS can then be transferred to another household. The cooperative charges an installation fee, Php 1,000 (USD 21.33) in Cabadiangan and Php 1,200 (USD 25.60) in Pay-as, to cover the cost of pulling-out the system and installing it to the new household. Since the project was implemented in 2008, the local electric cooperative finally managed to install grid connections in these 
barangays. However, the cost of connecting to the grid is still expensive for many of these households because they are spread out and they have to pay for the cost of the physical connection from the main post to their house. Thus, many still prefer to use the SHS. But the existence of the grid allowed the program to expand in its scope in the ARC. Households from nearby sitios that were once not prioritized by the program can have a chance to avail of the refurbished SHS, as long as they are members of the cooperative.

\subsection{Tabuk City: Sitio Makilo in Brgy. Calaccad}

Calacaad is a barangay of Tabuk City in the Province of Kalinga and remains rural with 1,339 residents [6]. Sitio Makilo is a farming community located in the southernmost part of Calaccad, close to Kalinga-Mountain Province border. Because of its very remote location, the route from Calaccad proper can only be traversed on a motorbike and requires several river crossings. Figure 5 is a typical home in the community.

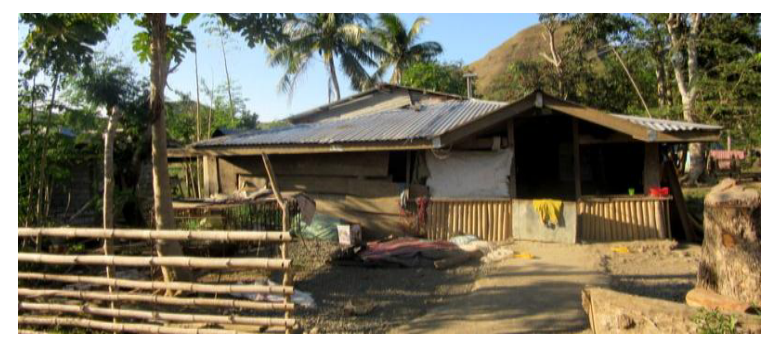

Figure 5. Typical house with a $30 \mathrm{~W}$ solar PV system.

Table 2 summarizes the project implementation in Sitio Makilo. Identification and consultations with the community by DOE were conducted in coordination with the local electric cooperative, Kalinga Apayao Electric Cooperative (KAELCO). Also, Kalinga Apayao State College is the DOE-Accredited Renewable Energy Center (AREC) that led the implementation of the program.

The subsidized cost of the $30 \mathrm{Wp}$ SHS was priced at Php 5,000 (USD 106.64). This amount was intended for the operations and maintenance costs of the SHS and was managed by the Makilo Solar Home System Association (MASOHOSA). It was decided by DOE that each household make an initial payment of Php 1,000 and the remaining amount be paid in an instalment basis during the harvest season, which occurs at least twice in a year.
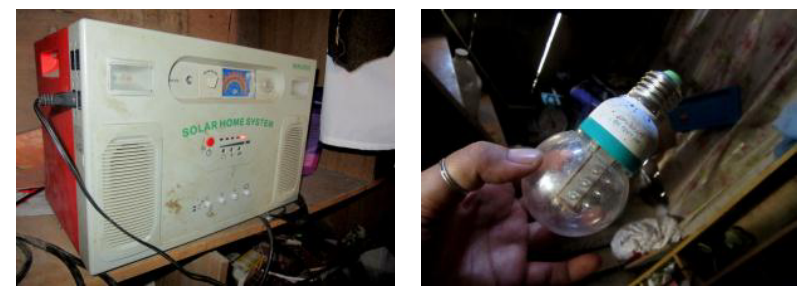

Figure 6. The SHS charge controller with radio feature, and the $12 \mathrm{~V}, 1.2 \mathrm{~W}$ LED bulb that came with the SHS.

The DOE conducted seminars to introduce the technology to the households. However, in the focused group discussion (FGD) conducted for this study, the
FGD participants all agreed that maintenance was not explained well during the seminar. They rely on the knowledge of the electrician in the community to troubleshoot the system when the need arises.

Currently, all 124 households continue to use their SHS even though many have already encountered problems since the SHS was installed. Despite the difficulty in acquiring replacement parts, the community managed to find substitutes though sometimes they resort to more expensive parts, like the use of truck batteries or the $13 \mathrm{~W}$ LED bulbs. The SHS originally came with 3 pieces of $3 \mathrm{~W}$ LED and 1 piece of $1 \mathrm{~W}$ LED bulbs. Figure 6 shows the charge controller and the LED bulb that came with the PV system.

Table 2. DOE-HEP implementation in Sitio Makilo.

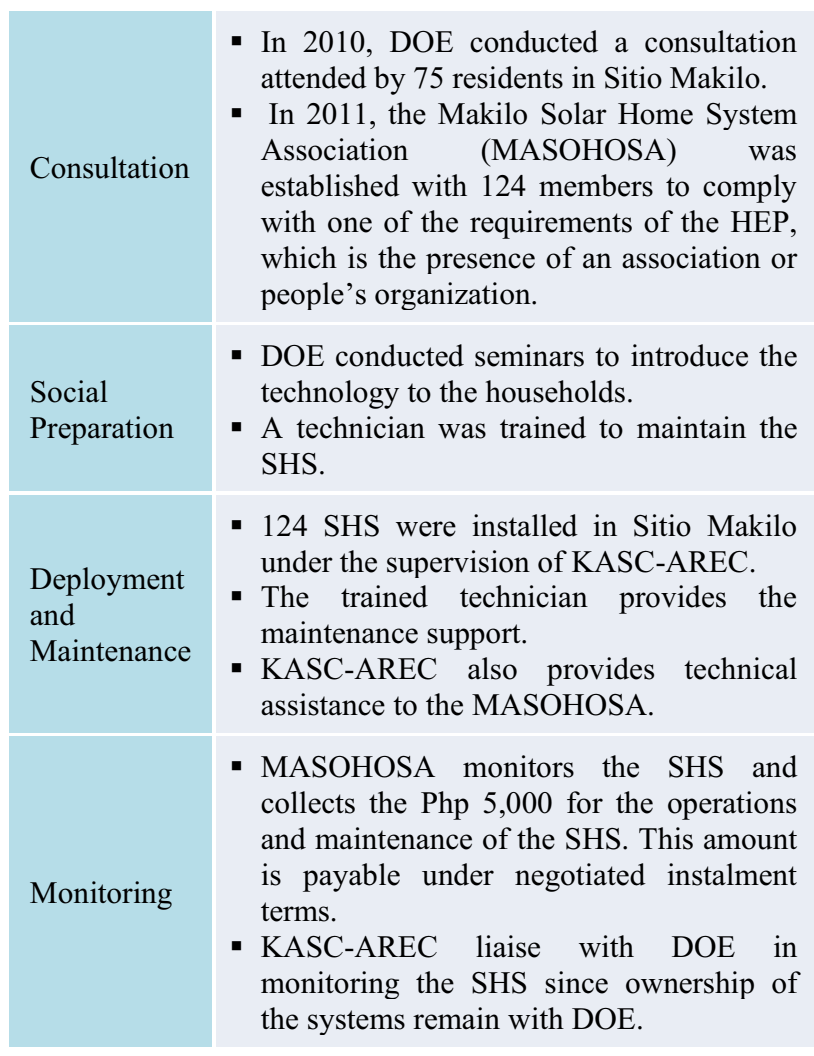

Ownership of the SHS remains with the DOE, as of Feb 2015. The MOA is not clear whether the ownership will be transferred to the MASOHOSA. Also, now that the sitio is electrified, it is not clear to the MASOHOSA if the systems must be transferred to unelectrified households or they can remain with the original subscribers even if they are already connected to the grid.

Under the HEP, the solar home system consists of a solar panel, a charge controller with integrated radio, a sealed type battery and 4 bulbs ( 3 units of $3 \mathrm{~W}$ bulb and 1 unit of $1 \mathrm{~W}$ bulb). The SPOTS program has a similar type of system but instead of LED, fluorescent lamps were provided with the SHS and the charge controller or system regulator is operated through a pre-paid scheme. However, some SPOTS beneficiaries in Pay-as feel that the system should be bigger to power other appliances. In Cabadiangan, four lamps were reduced to three to control the usage of the system. This means that the system was not sized properly or that the load is more than what was 
designed. Also, the prepaid mechanism was ineffective because delinquent subscribers found a way to modify the regulator in order to by-pass the system.

For the maintenance of the SHS, households in Cabadiangan and Pay-as were taught basic maintenance such as wiping the panels and keeping batteries in a dry place. Households in Sitio Makilo however feel that the maintenance of the SHS was not explained well during the seminar. Also, there was no clear policy on the ownership and responsibility of the repair and maintenance of the solar home system.

The community association keeps track of the monitoring frequency of the trained technician and the number of functional solar home systems. The most common problem is the availability of replacement parts. Parts used to build the SHS are imported and batteries designed for solar applications are also not readily available to the community. Some prepaid regulators in the SPOTS program stopped working after 2-3 years and were not replaced. Also, there were no replacements for the fluorescent lamps/tubes. The size is different from those available in local hardware stores. This is also true in Sitio Makilo as there are no suppliers for LED bulbs and batteries that are compatible with their system. They had to resort to LED bulbs with higher wattage.

In all three communities, savings and potential income through the programs were the emphasis in the seminars conducted during the social preparation. For instance, the monthly fees should be the same or less than the amount spent on kerosene because the sustainability of the program relied on the households' capacity to pay. Also, the RE technology enabled the household to increase their hours of productivity, which directly or indirectly affected their livelihood. A commissioned study [4] reported that rural electrification, in general, increased the per capita income in beneficiary areas by $36 \%$ based on the 2010 Annual Poverty Indicator Survey. This is typical in developing countries where the economic impact of the RE technology being introduced is the primary consideration. Unlike in developed countries where community-based RE projects are undertaken as a step towards sustainable energy generation to mitigate climate change [7].

\section{Conclusion and Recommendations}

This study looked into three community-based SHS projects in the Philippines. Project implementation requires several key elements to achieve community adoption and sustainability: (1) Conduct consultation with the community, which includes resource and site assessment to properly design the SHS, and social and environmental impact assessment to make sure that the RE technology and its scale will not have an adverse impact on the environment and on the community, (2) Social preparation includes educating the community members for technology adaptation, especially where local community is ethnic minority group. The system should be simple so that the technology can be transferred to the locals. Also, highlight the benefits to convince the community members that the technology is viable and useful to them, (3) Training the community members as local personnel to manage the project, its implementation and its maintenance. Technology transfer must be ensured and safety must be emphasized in these trainings, (4) Financing can be obtained from government, foundations and international grant giving bodies. However, this should be limited to subsidies. The community or its members still need to have counter funding for the project so they have a sense of ownership of the system. This ensures that they will take care and make use of the system properly, (5) Operations and maintenance is the responsibility of the cooperative within the community. Upon turnover, the cooperative continues to manage and monitor the project. Thus, capacity building in all aspects of the projects must be conducted properly, (6) Local Materials/Locally available components must be used so that in case of damages and repairs, parts of the system that need to be replaced are easily available to the community. The implementing agency can also partner with a local hardware/electrical store who can guarantee that replacement parts are always on stock, and (7) Sustainability of the project is ensured if there is an income generating component to the project. In the cases presented, the beneficiaries are the community associations, and the monthly subscription fee for operations and maintenance of the SHS sustains the project. Also, the SHS subscription fees must be less than what the household used to pay for lighting so that the households can afford to pay the monthly fees.

\section{Acknowledgement}

This work was supported by the Toyota Foundation under the International Grant Program [D14-N-0082].

\section{References}

1. Energy Sector Accomplishment Report. Department of Energy, 2013. Web. 15 Oct. 2015.

2. D. Renné, P. Gray-Hann, R. George and L. Brady. Assessment of Solar Resources in the Philippines: Internal Review Report. National Renewable Energy Laboratory, 2000. Print.

3. Solar Power Technology Support Project (SPOTS) Project Completion Report. Department of Agrarian Reform, 2005. Print.

4. A.M. Navarro. Cost Efficiency and Effectiveness of the Sitio and Household Electrification Program. Department of Budget and Management, 2013. Web. 31 Dec. 2015.

5. D. Waldron, et.al. Guide to the Framework for Strategic Sustainable Development. Blekinge Institute of Technology, 2008. Web. 17 Feb. 2016.

6. C.N. Ericta. "The 2010 Census of Population and Housing Reveals the Philippine Population at 92.34 Million." Philippine Statistics Authority, 14 Apr. 2012. Web. 31 Dec. 2015.

7. L. Greenius, E. Jagniecki, K. Thompson. Moving Towards Sustainable Community Renewable Energy: A Strategic Approach for Communities. Blekinge Institute of Technology, 2010. Thesis. 